\title{
DESIGN AND ANALYSIS OF SPINDLE FOR SPECIAL PURPOSE MACHINE
}

\author{
Ashwini V Karad ${ }^{1}$, Nandkumar A Rawabawale ${ }^{2}$, Sachin M. Nagure ${ }^{3}$ \\ ${ }^{1} P G$ Student of Department Of Mechanical Engineering, Ambajogai, Maharashtra \\ ${ }^{2}$ Associate Professor Department of Mechanical Engineering, Ambajogai, Maharashtra \\ ${ }^{3}$ Assistant Professor Department of Mechanical Engineering, Ambajogai, Maharashtra
}

\begin{abstract}
This paper presents a designing of spindle and frequency analysis in polishing machine .spindle is the heart of machine, that's why to get extra accurate work, it is necessary to study the spindle, in this paper designing the spindle and performing the study over it. The present interest in raising a manufacturing ability at the mixed scales is important to a number of investigations scared by the progress of special purpose machine tools. The difficulty with most SPM is the quantity of vibration that is transmitted during the spindle, which affects the quality of surface finish and the dimensional accuracy report to the work piece being machined. SPM is a special purpose machine totally used in two wheeler automobiles. The core purpose of this paper is to design and perform finite element analysis of the SPM.
\end{abstract}

Keywords - Special Purpose Machine, Machine Tool Manufacturers, Work Accuracy, Design Calculations

\section{INTRODUCTION}

In machine tools, a spindle is rotating axis of the machine, which often has a shaft at its heart. The shaft itself is called a spindle, but also, in shop-floor perform, the word frequently is used metonymically to pass on to the whole rotary unit, with not only the shaft itself, but its bearings and rather attached to it. Special purpose machines are designed and manufactured for exact jobs and as such never produce in bulk. Such machines are judgment rising use in industries. The way for designing such machines would clearly be quite different from those under for mass produced machines [4]. In this paper two software used for the spindle model one is PRO-e for 3D modeling and other is ANSYS for 2D modeling. For calculating Deformation on different load the ANSYS software is very helpful.

\section{MODELING AND ANALYSIS OF SPINDLE}

ANSYS is very powerful tool to capture the design intent of models by understanding fundamental concepts that define the software and why they exist. Firstly, we created a solid model using designing software Pro-e. Then the model is imported into ANSYS and analyzed by applying necessary conditions, which were considered in designing it and then checked deformation in different load. The specifications required for the design are taken from the drafted design.
Spindle contains two bearings on each side to get strong support and handle maximum load on spindle.

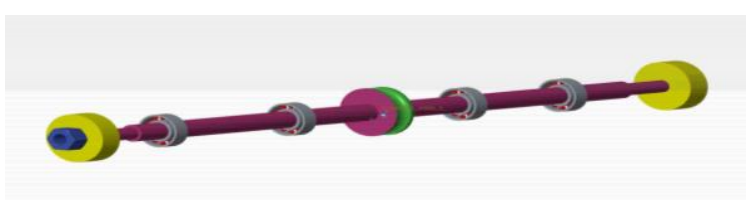

Fig.2: Solid Model of Existing \& Modified Roller

\subsection{Dimensions of Spindle}

Following dimension are used to draw the solid model. Outer diameter of a spindle Length of a spindle $50 \mathrm{~mm}$ Outside step $1000 \mathrm{~mm}$ Middle Step (pulley mounting) - $70 \mathrm{~mm}$

\subsection{Analysis of Spindle}

- Preprocessing

- Create the solid model.

- Choose the element type.

- Mesh the model.

- Element Type - spindle

Young's modulus: $2.1 \times 10^{5} \mathrm{MPa}$

Density: $\quad 7.850 \times 10^{-3}$ tons $/ \mathrm{mm}^{3}$.

Poisson's Ratio: $\quad 0.3$

Fig.1: Solid Model. 


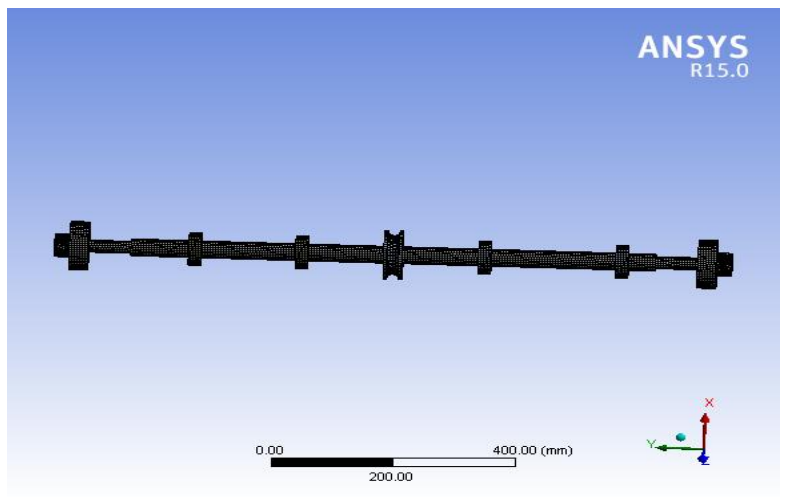

Fig.3: Spindle Model.

\subsection{Load: $400 \mathrm{~N}$}

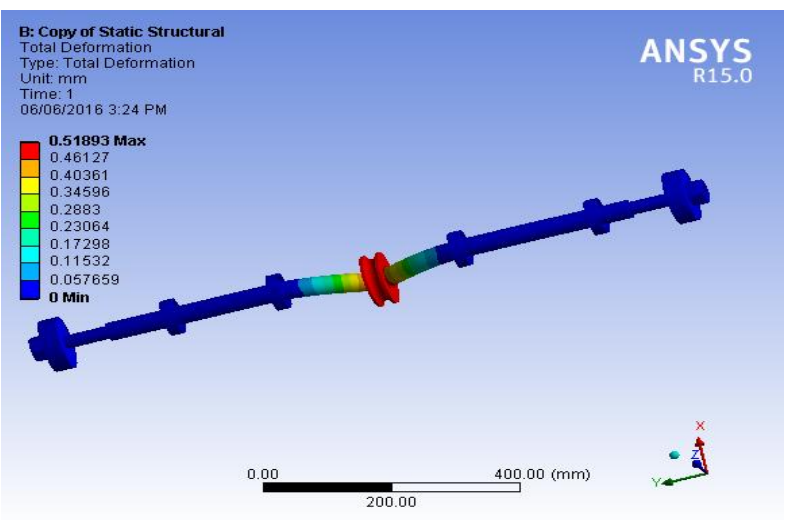

Fig.4: Deformation of Static Structural At load 400N.

Load Apply: $400 \mathrm{~N}$

Deformation:

i. $\quad \operatorname{Min}=0 \mathrm{~mm}$

ii. $\quad$ Maximum $=0.5183 \mathrm{~mm}$.

\subsection{Equivalent Von-Mises Stress at $400 \mathrm{~N}$}

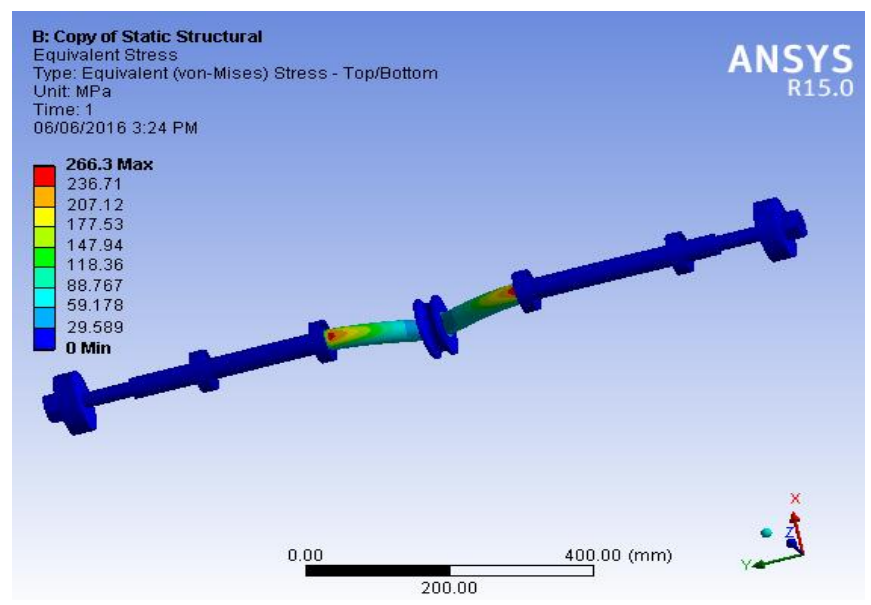

Fig.5: Equivalent Stress at Load 400N.

Load Apply: $400 \mathrm{~N}$

Deformation:
i. $\quad$ Min $=0 \mathrm{~mm}$
ii. $\quad$ Maximum $=266.3 \mathrm{~mm}$.

\subsection{Load: $600 \mathrm{~N}$}

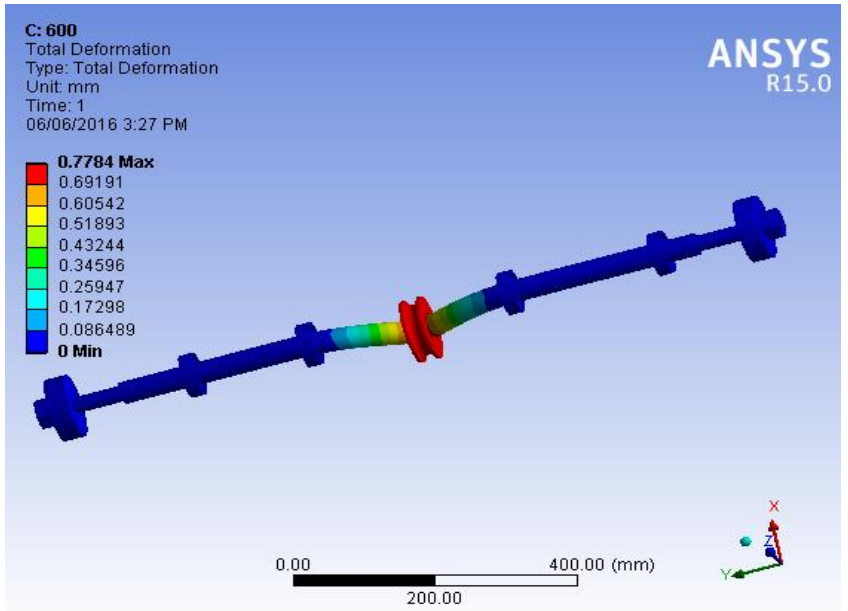

Fig.6: Total Deformation at Load 600N

LOAD APPLY: $600 \mathrm{~N}$

Deformation:

$$
\begin{aligned}
\text { i. } & \text { Min }=0 \mathrm{~mm} \\
\text { ii. } & \text { Maximum }=0.77 \mathrm{~mm}
\end{aligned}
$$

\subsection{Equivalent Von-Mises Stress at $600 \mathrm{~N}$}

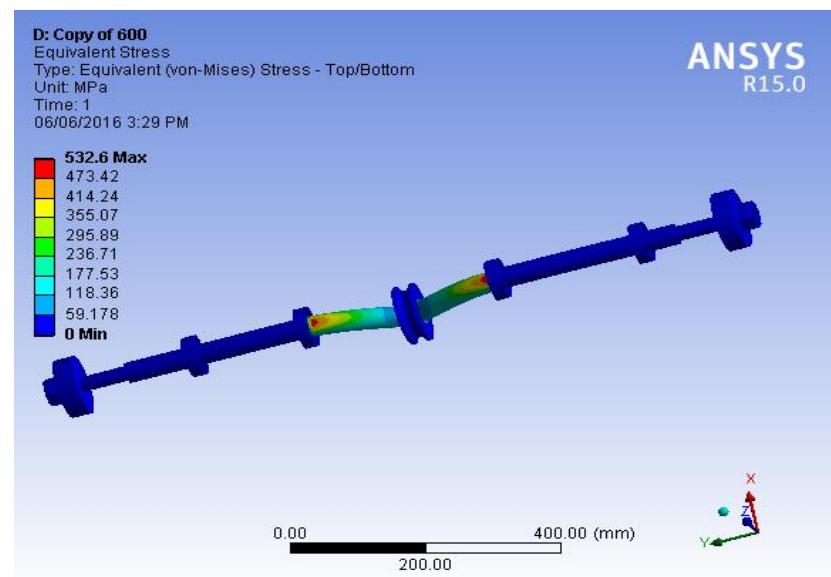

Fig.7: Equivalent Stress

LOAD APPLY: $600 \mathrm{~N}$

Deformation:

$$
\begin{aligned}
\text { i. } & \text { Min }=0 \mathrm{~mm} \\
\text { ii. } & \text { Maximum }=532.6 \mathrm{~mm}
\end{aligned}
$$

\section{NATURAL FREQUENCY ANALYSIS}

Natural Frequency applied on spindle in Fig 8, 9 shows the model analysis at various frequencies and element behavior respectively. Fig 8 shows model at $9.13 \mathrm{~Hz}$ frequency and element behavior. Red color zone indicates the deformation of spindle having range from $0 \mathrm{~mm}$ [min.] to $41.1 \mathrm{~mm}$ [max.]. 


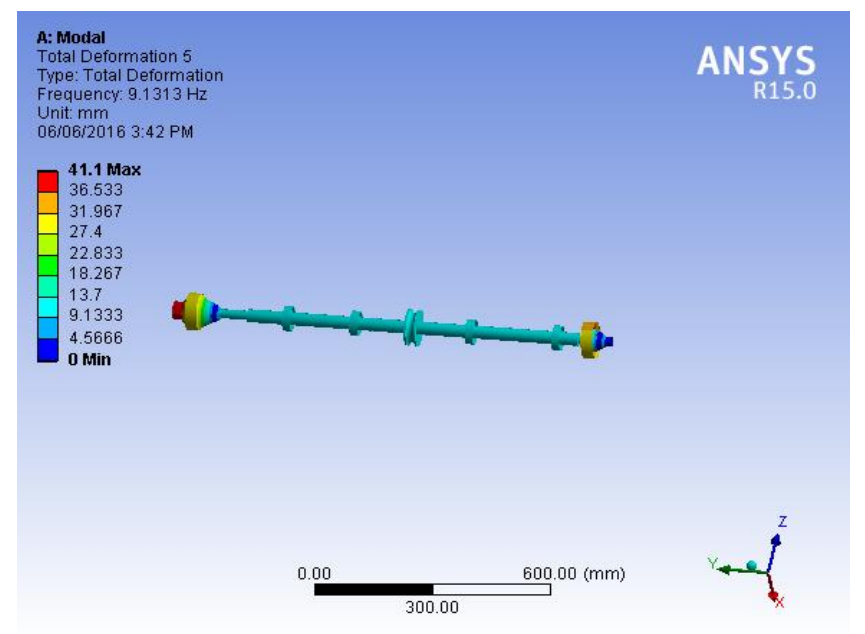

Fig.8: Nodal Displacement Solution for Frequency $(9.13 \mathrm{~Hz})$

Fig.9 shows the modal analysis at the $16.28 \mathrm{~Hz}$ frequency \& element behavior. Red color zone indicates the deformation of existing roller follower having range from $61.874 \mathrm{~mm}$ [min.] to $69.608 \mathrm{~mm}$ [max.]. Blue color zone indicates the deformation of existing roller follower having range from 0 $\mathrm{mm}$ [min.] to $7.7342 \mathrm{~mm}$ [max.].

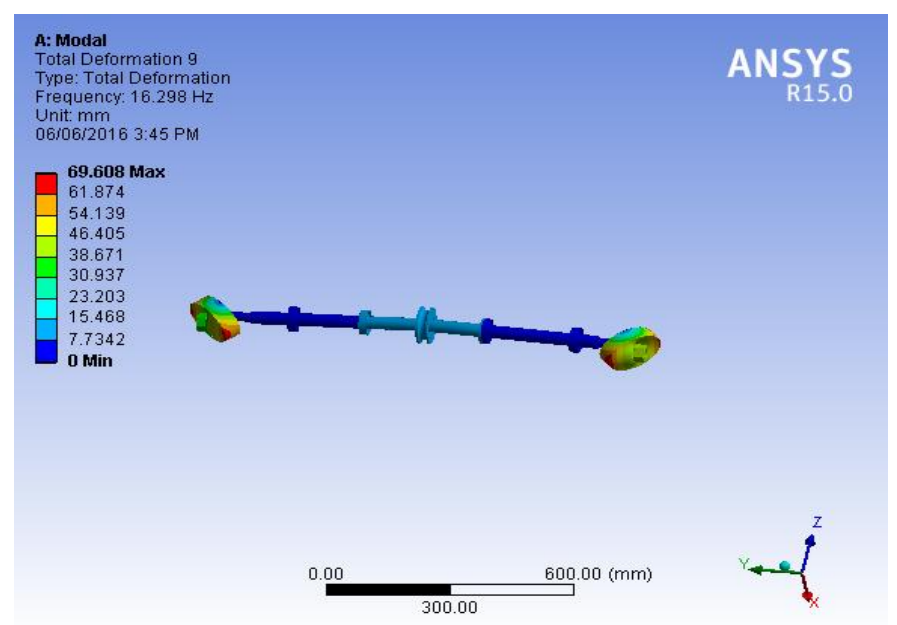

Fig .9: Nodal Displacement Solution Frequency

The table.1 shows the frequency range for two sets of the spindle with line contact which is fixed and this same frequency range used in the modified roller follower.

Table 1: Two Modes Of Vibration

\begin{tabular}{|l|l|l|}
\hline Set & Frequency & Exact frequency \\
\hline 1 & $0 \mathrm{~Hz}-10 \mathrm{~Hz}$ & $9.13 \mathrm{~Hz}$ \\
\hline 2 & $10 \mathrm{~Hz}-20 \mathrm{~Hz}$ & $16.298 \mathrm{~Hz}$ \\
\hline
\end{tabular}

\section{CONCLUSION}

$3 \mathrm{~d}$ model of the SPM assembly is done using pro-E software and Finite element study is carried out using ANSYS. Design calculations are performed to calculate the operating loads. Finite element analysis was done to confirm the design based on analysis the spindle deflections.
Static Analysis Result The stress study of existing roller and modified roller is done. The Load value for existing spindle is $400 \mathrm{~N}, 600 \mathrm{~N}$ these two loads are apply on spindle and there deformation is analyze and results are mention below

Table 2: Applied Load Vs. Deformation

\begin{tabular}{|l|l|l|l|}
\hline SR. & APPLIED & \multicolumn{2}{|l|}{ DEFORMATION } \\
\cline { 3 - 4 } NO. & LOAD & MIN $(\mathrm{mm})$ & MAX $(\mathrm{mm})$ \\
\hline 1 & $400 \mathrm{~N}$ & 0 & 0.5163 \\
\hline 2 & $600 \mathrm{~N}$ & 0 & 0.77 \\
\hline
\end{tabular}

\section{ACKNOWLEDGMENT}

I feel great pleasure to present this Paper "Design and Analysis of Spindle for Special Purpose Machine".

I would like to thank Prof. N.A. Rawabawale and S.M. Nagure for their constant support, motivation and continuous encouragement throughout the paper work.

I am thankful to Dr. Veeresh G. K. for his support and motivation.

I express sincere gratitude to honorable Principal Dr. B. I. Khadakbhavi for his kind cooperation.

\section{REFERENCES}

[1] H. L. Xie, H. M. Guo, Q. B. Wang, Y. X. Liu, "The Spindle Structural Optimization Design of HTC3250 $\mu$ n NC Machine Tool Based on ANSYS", Advanced Materials Research, Vols. 457-458, pp. 6064, 2012

[2] Vincent Gagnol, Belhassen C. Bouzgarrou, Pascal R ay, Christian Barra, "Dynamic Analyses and Design Optimization of High-Speed Spindle Bearing System" Advances in Integrated Design and Manufacturing in Mechanical Engineering II, pp 505-518,

[3] Smith, S.; Winfough, W.; Young, K.; Hally, J. “ The Effect of Dynamic Consistency in Spindles on Cutting Performance, Proceeding of the ASME" Manufacturing Engineering Division 2000, MED-Vol. 11, 927-933.

[4] Mr. Sakate P.R.1 Mr. Jadhav A.S., Prof. Bamankar P.B.3 Miss. Jagadale A.A.4 Miss. Bhosale, "A Review on Multi Spindle Drilling Special Purpose Machine with Respect to productivity" P.S.5 JSRD. 